\title{
Closing well: national and international humanitarian workers' perspectives on the ethics of closing humanitarian health projects
}

Matthew Hunt ${ }^{*}$ (D), Lisa Eckenwiler ${ }^{2}$, Shelley-Rose Hyppolite ${ }^{3}$, John Pringle ${ }^{4}$, Nicole Pal ${ }^{5}$ and Ryoa Chung ${ }^{6}$

\begin{abstract}
Project closure is a core feature of humanitarian action. However, how decisions to end projects are made, and how closure is planned and implemented, has implications for upholding ethical commitments, and can have positive or negative consequences for affected communities, local stakeholders, and humanitarian organizations and their staff. To better understand the ethical dimensions of closing humanitarian projects, we undertook an investigation of national and international humanitarian workers' experiences.

Guided by interpretive description methodology, we conducted an exploratory qualitative study with two rounds of semi-structured interviews. Four national and five international staff of non-governmental organizations with experience of humanitarian health project closure took part. The participants had diverse professional roles and disciplinary backgrounds. All participants took part in the first round of interviews which focused on experiences and perceptions of ethics and project closure. Analysis of these interviews contributed to the development of a draft "ethics guidance note." Five of the participants took part in the second round of interviews which focused on receiving feedback on the draft guidance note. We used constant comparative techniques and a recursive approach to data collection and analysis. In this article, we draw on both rounds of interviews to present findings related to how participants understood and experienced ethical responsibilities, challenges, and opportunities for humanitarian project closure.

We identified six recurrent ethical concerns highlighted by interviewees regarding closure of humanitarian projects: respectfully engaging with partners and stakeholders, planning responsively, communicating transparently, demonstrating care for local communities and staff during project closure, anticipating and acting to minimize harms, and attending to sustainability and project legacy. We present these ethical concerns according to the temporal horizon of humanitarian action, that is, arising across five phases of a project's timeline: design, implementation, deciding whether to close, implementing closure, and post-closure. This exploratory study contributes to discussions concerning the ethics of project closure by illuminating how they are experienced and understood from the perspectives of national and international humanitarian workers. The interview findings contributed to the development of an ethics guidance note that aims to support project (Continued on next page)
\end{abstract}

\footnotetext{
* Correspondence: matthew.hunt@mcgill.ca

'School of Physical and Occupational Therapy, McGill University, and Centre for Interdisciplinary Research in Rehabilitation, 3654 Promenade Sir William Osler, Montréal, QC H3G 1Y5, Canada

Full list of author information is available at the end of the article
}

\section{Springer Open}

(ㅇ The Author(s). 2020 Open Access This article is licensed under a Creative Commons Attribution 4.0 International License, which permits use, sharing, adaptation, distribution and reproduction in any medium or format, as long as you give appropriate credit to the original author(s) and the source, provide a link to the Creative Commons licence, and indicate if changes were made. The images or other third party material in this article are included in the article's Creative Commons licence, unless indicated otherwise in a credit line to the material. If material is not included in the article's Creative Commons licence and your intended use is not permitted by statutory regulation or exceeds the permitted use, you will need to obtain permission directly from the copyright holder. To view a copy of this licence, visit http://creativecommons.org/licenses/by/4.0/. 


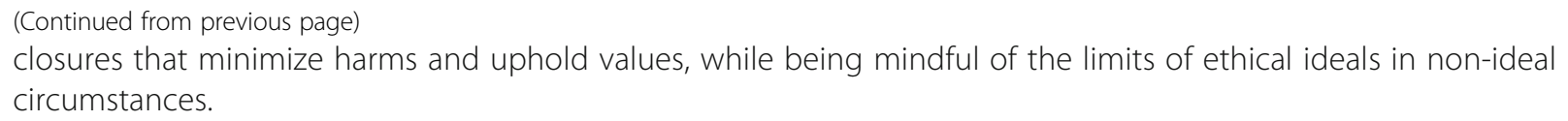

Keywords: Ethics, Exit strategies, Humanitarian action, Non-governmental organizations, Project closure, Moral distress

\section{Background}

Humanitarian projects are designed to be transitory. They are interventions that are implemented in response to a crisis, such as war or disaster, with the intention that they will be transitioned to a development approach, handed over to local agencies or authorities, or shut down when objectives have been met. The duration of humanitarian projects varies considerably due to a range of factors related to the crisis context, organizational mandates, availability of funding, and continued permission from state or non-state actors. Many projects last weeks or months, while others are active for years, especially in situations of protracted armed conflict. There is variation, too, in how projects are closed. Some are closed abruptly due to force majeure incidents, such as an acute exacerbation of hostilities or a major security incident, or as a result of a management decision to close out the project quickly. However, most are closed in a more structured and deliberate manner, including situations when projects are handed over, transitioned, or phased down (gradual scaling back of the project, sometimes leaving a small remnant in place in case the crisis flares up again). In this paper, we focus on the latter set of project closures.

The closing of a humanitarian project has been described by a range of authors as an especially difficult phase, and one that gives rise to ethical challenges for humanitarian organizations, their staff, and organizations that they partner with on program delivery or for a project handover (Lee and Özerdem 2015; Ford and Bedell 2001). Several accounts of how project closures have been experienced by local communities have also been published. For example, Anderson, Brown, and Jean quote an Angolan government official who reported that if closure had been done with greater transparency and predictability, it would "not be cause for such sorrow" within the affected communities (Anderson et al. 2012 p. 17). In a case study in Chad of how a major international humanitarian medical organization was perceived by different groups, "many respondents expressed their concern about the lack of coherence in exit strategies", including in a situation where after closure "not only did patients lose access to the medical supply, the quality of care go down, and the number of doctors/medical personnel decrease dramatically, but the population also had to pay for all services and drugs" (Abu-Sada and Mambetova 2012 p. 25). Similar concerns were reported by refugees when a camp was being closed in Northern Uganda (Orach and De Brouwere 2005). These narratives illustrate the sorts of challenges associated with closing humanitarian projects, and the consequences for members of affected populations.

There have been efforts to develop organizational (Gerstenhaber 2014; IFRC 2016; World Health Organization n.d.) and interagency guidance (Global CCCM Cluster 2014) related to closure of projects and programs. Several authors have also developed normative accounts of justice and obligations for humanitarian project closure. Hurst, Mezger, and Mauron consider processes of opening and closing humanitarian projects from the perspective of ethical resource allocation (Hurst et al. 2009). Fuller identifies the importance of considering both the instrumental and intrinsic value of humanitarian projects (Fuller 2006). Rubenstein argues that humanitarian organizations have special obligations to the communities they have been serving, basing her argument on humanitarian organizations' functioning in "somewhat-governmental" roles as second-best actors (Rubenstein 2015 p. 55). Finally, Hunt and Miao (2018) - on Richardson's concept of moral entanglements (Richardson 2012) to develop an account of ethical obligations based on the characteristics of particular humanitarian projects.

To date, no empirical study has focused on national and international humanitarian workers' experiences and perceptions of the ethical dimensions of humanitarian project closure. We therefore undertook an exploratory interview-based study to better understand how humanitarian workers experience ethical concerns related to closing projects. The interviews also contributed to the development and refinement of an ethics guidance note aimed at supporting efforts at project closure.

\section{Methods}

We conducted an exploratory interpretive description study (Thorne 2016), grounded in a constructivist approach to inquiry (Lincoln et al. 2011), and based on individual key informant interviews. Interpretive description is a qualitative research methodology originally developed in nursing sciences that seeks to better understand a given phenomenon by illuminating patterns and characteristics of subjective experience, while accounting for difference (Thorne 2016). It is particularly oriented to the examination of topics related to praxis in applied disciplines. Within a constructivist paradigm, realities are understood to be socially and experientially based and local in nature, and that researchers and participants co-construct 
knowledge (Lincoln et al. 2011). Our interdisciplinary research team (bioethics, medicine, nursing, political philosophy, rehabilitation) partnered with the humanitarian non-governmental organization Médecins $d u$ Monde (Doctors of the World)-Canada to develop the project. Through the interviews we aimed to explore, from the perspective of national and international humanitarian workers, processes of humanitarian project closure and what values, principles, and methods support ethically robust closure of humanitarian health projects. National staff include people working in their country of origin for a humanitarian organization, while international staff are people engaged in humanitarian action in another country. In this article, we present an analysis of participants' narratives and perceptions of ethical concerns related to project closure across the phases of a humanitarian project's timeline. These concerns include features of project closure that participants associated with ethical responsibilities (including obligations and commitments), as well as opportunities and challenges for upholding them.

The interview-based study is part of a larger project that included a review of the gray and academic literature about ethics and project closure (Pal et al, 2019) and development of an ethics guidance note oriented toward people involved in or affected by humanitarian project closures. The research team drew on the literature review, the semi-structured interviews, and the team's wider engagement with literature in the fields of humanitarian ethics, bioethics, political philosophy, and political science, in order to develop the ethics guidance note. A draft version of the guidance note was reviewed during a workshop with ethics scholars, humanitarian workers, and graduate students before being finalized. A condensed and an extended version of the guidance note are available at https://humanitarianhealthethics.net/ethicsand-the-closure-of-humanitarian-healthcare-projects/.

Inclusion criteria for interview participants included having worked as a national or international staff member for a humanitarian non-governmental organization, having experience of humanitarian health project closure, and being able to participate in an interview in English or French. Participant recruitment included four steps. We began by asking our partner organization to share information about the study with individuals who might be interested and eligible to participate (1 participant identified). We then recruited participants through the professional networks of the research team (5), through advertisement of the study on social media and our website https://humanitarianhealthethics. net (1), and by asking participants in the study to suggest others who might be interested to take part (2, suggested by different participants).

In total, nine people participated in the study. All had experiences closing humanitarian projects and had held roles including country coordinator, head of mission, project manager, operations manager, quality advisor, and human resources officer. The professional and disciplinary training of participants was diverse, ranging from medicine and public health, to agriculture and accounting. They had experienced closures ranging from the exiting of an entire organization at the national level, to the closing of health clinics at the village level. There was a wide range of experience in humanitarian action amongst the participants, from two people who had worked with a single humanitarian organization, in a single country, to three who had each participated in humanitarian responses to more than ten crises over several decades. While our primary focus was on healthrelated humanitarian projects, participants also discussed experiences with other types of humanitarian projects (e.g., focused on water and sanitation), or projects that were not specific to healthcare (i.e., a camp for displaced persons). The nine participants included five international humanitarian workers and four national staff members (one of whom subsequently became an international staff for the organization in several other countries).

We carried out two rounds of semi-structured interviews with separate interview guides. All participants took part in the first interview which explored their experiences and perspectives related to ethics and humanitarian project closure. Example questions include the following: in what ways have you experienced decisions to close a humanitarian project? What was the context? Why was the decision made and how? How was the decision implemented? What do you think was done well in this situation? Were there ethical challenges that you or others faced? Five of the participants were interviewed a second time, 1-3 months after the first interview (the other four participants did not take part in a second interview because they were unavailable to do so, or an interview could not be scheduled prior to the feedback workshop). Before the second interview, we sent the participant the latest iteration of the ethics guidance note (as described above). During the second interview, the participant was asked to provide feedback on the draft ethics guidance note and invited to elaborate further on their experiences of project closure.

Interviews were conducted from October 2018 to May 2019 by Skype, phone, or in-person, in English or French, and all were audio-recorded. First round interviews lasted between 60 and $98 \mathrm{~min}$ and were transcribed verbatim. Second round interviews lasted between 44 and $58 \mathrm{~min}$ and were not transcribed given that the focus of the interview was on receiving feedback on the ethics guidance note. The interviewer took notes during and after these interviews.

Inductive data analysis of the round one interviews was initiated as soon as transcriptions were available. We used constant comparative techniques within and 
across interviews, and a recursive approach to data collection and analysis, whereby analysis of early interviews was utilized to refine the interview guide for later interviews (Thorne 2000). Synopses of each interview were written to summarize key points of discussion and insights from the interview. Initial coding was developed by one team member based on the first two interviews and then circulated to the rest of the team for further input. A second team member independently coded two transcripts in order to triangulate the analysis, and this input was used to refine the code book (the set of labels that were used to inductively code the full set of transcripts). We used analytic techniques such as recurrent close reading of transcripts and synopses, data display tables, and concept maps. To ensure the comprehensiveness of this process, a team member then listened again to the recordings and reviewed all notes taken during and after the interviews.

This study was reviewed and approved by the Institutional Review Board of McGill University's Faculty of Medicine. All participants signed an informed consent form.

\section{Results}

All the participants described closure as a crucial component of humanitarian action, and a challenging aspect of their work as national or international humanitarian workers. Overall, they described some closures that went smoothly and presented examples of good practice to be emulated elsewhere, and they also related closures that gave rise to significant ethical issues. The challenge of closing well is reflected by an international humanitarian worker with over 30 years of experience in humanitarian action who expressed that closing projects-including transitioning and handing over-is "always the hardest part" and something that humanitarian organizations need to do better. Despite acknowledgment of these challenges, participants held that it was a topic that received insufficient discussion in the humanitarian sector. Another participant affirmed this when she suggested that as humanitarians, we "don't ask ourselves these questions [about ethical project closure] enough."

In the sections that follow, we present findings related to how participants understand and experienced ethical concerns across the temporal horizon of humanitarian projects, which we have divided here into five project phases (which we acknowledge may not have sharp boundaries in practice): design, implementation, deciding whether to close, implementing closure, and post-closure. Across these phases, we identified six recurrent ethical concerns associated with closing projects well: respectfully engaging with partners and stakeholders, planning responsively, communicating transparently, demonstrating care for local communities and staff during project closure, anticipating and acting to minimize harms, and attending to sustainability and project legacy. Selected verbatim quotations are included to illustrate aspects of our analysis.

\section{Design: "closing a project begins right on day one"}

Many participants strongly emphasized that closing should be built-in to the project from the outset, and therefore, that "closing a project begins right on day one." Thus, project design and funding proposals should already include attention to how the project will be ended and what will be its legacy, with closure and contingency plans "really thought through, really discussed from the beginning." This proactive and anticipatory approach was suggested by participants as a means to decrease uncertainty by anticipating and designing a preliminary roadmap towards closure while also enabling responsiveness to changing circumstances, since "the earlier you plan for it, the better prepared you can be to take it in your stride" and adapt to alter plans if needed. Pointing to the consequences of insufficient planning, a national staff member described a project focused on populations displaced by armed conflict in East Africa for which closure went unconsidered in the planning phase and was only mentioned in the risk management framework. He reported that, when the project was ended early, the lack of planning for closure during the design phase contributed to confusion and frustration.

Anticipating project closure and ensuring that there are robust plans in place may also require engaging with donors from the outset. A national staff participant who was a senior manager for an international nongovernmental organization's (NGO) country-level operations, reported negotiating with donors after a major disaster in South Asia to ensure that funding would be in place to "ensure that our engagement with communities didn't end abruptly." She reported that some donors supported and encouraged such an approach, while others tended to award short contracts because they were looking for "quick wins" which made it harder to plan for an effective handover or transition, and did not allow the possibility of "building in sustainability mechanisms."

Engagement with key stakeholders during the design phase was also emphasized by participants. In discussing harms associated with closure, a participant described how you can "mitigate them by more comprehensive early engagement with government and local partners. I think you set up, you position the early emergency response for more sustainability by integrating [...] the local NGOs and sub-national health infrastructure." This participant went on to describe ways that such engagement orients humanitarian agencies to invest in local structures and systems, rather than setting up their own parallel systems which could impede sustainability later 
on. Similarly, another international worker who had worked with international NGOs and within the UN system, described how humanitarian agencies should avoid a "top-down Western approach of sort of parachuting into a situation and then setting up structures that are duplicating" those that already exist in the locale. A national staff member explained that having government agencies participate from the start was valuable since they were ultimately responsible for ensuring service access for communities. She reported that her organization is "designing more and more projects that enable us to, from the day one, to really bring in the duty bearer [the government] into the conversation, so that as the project ends, the duty bearer is then able to pick up and continue some of this." In these ways, project design can lay the groundwork for a project closure that supports the sustainability of humanitarian intervention.

\section{Project implementation: aiming for an eventual "soft landing for beneficiaries"}

With closure already anticipated in the design phase, participants suggested that it should remain a key consideration throughout the project's implementation phase. A national staff participant described the importance of engaging all members of the team, as well as project partners, in this process so that planning for closure is continuous and understood to be a shared responsibility. Participants proposed several strategies to achieve these goals, including learning from experiences in other projects, being oriented by the design phase planning and updating plans when necessary, and avoiding a "cookie-cutter" approach that fails to account for the local context. This process is also supported by regularly evaluating progress, and asking, "are there issues that we should address, whether we are going to leave or not, before arriving at project closure?"

Throughout the implementation of the project, the team can take steps to promote what a national staff member described as a "soft landing for beneficiaries" when the project eventually closes. For example, a participant described how even in an acute response initiated during an armed conflict, the team can gradually increase recovery-oriented activities from the early stages of the implementation process so that when the project does close, it will not be "like running at a hundred miles an hour delivering this gigantic or very broad variety of health services or water sanitation services" and then an abrupt stop.

Transparency of process and management of expectations are also important during the implementation phase. Several participants emphasized that humanitarian organizations need to clearly and repeatedly communicate the temporary nature of their project and its mandate. Such transparency was described as particularly critical when hiring local staff members so that expectations are clear. While the timeline of the project may not be known, or may shift due to unfolding circumstances, the fact that employment will end when the project is over is a crucial message. It was linked to avoiding harms for staff since they could better plan for the future, but also as a means of avoiding frustration and conflict when closure takes place. Throughout the implementation phase, opportunities to build the capacity of local staff can also contribute to benefits for the local community after project closure. One participant suggested that NGOs focus too much on training for international staff who already have many opportunities to advance their knowledge and careers, and that they should redirect these resources toward national staff whose increased expertise will continue to benefit the community even after the organization has left.

Difficult closures may also result from decisions made during the implementation phase. For example, a participant who had worked in over a dozen countries related several scenarios where rules related to contracts, employment benefits or taxation had not been correctly handled during the implementation of the project. She described these issues as avoidable and leading to important challenges during the closure phase. She also described them as reflecting a pattern of international humanitarian workers sometimes disregarding or being ignorant of local laws and procedures.

\section{Making the decision whether to close the project: "the tension is real"}

As a project progresses, a point will be reached when questions about project closure are raised and planning for closure accelerates. This point may be triggered by pre-determined indicators or external timelines (e.g., due to funding), or may be a more spontaneous development based on how the project has progressed. The participants described a range of scenarios when this stage was characterized by divergent perspectives about when (and if) closure should be initiated, and uncertainty about the best way to proceed. For example, several participants described situations when there was internal debate within the organization about whether to continue assisting the communities with whom they were already working or to shift their efforts to other communities with higher levels of need. Discussing the closure of a project that was initiated during armed conflict in West Africa, a participant described that, in such a situation, she was not sure "that a very good job can be done" of resolving the competing ethical concerns around project closure decision-making "because the tension is real."

Unless there are external pressures such as acute insecurity or a sudden cut in funding, many projects involve 
a period of deliberation before the decision to close the project is made. During this phase, participants identified engagement with local communities and stakeholders as a key means of demonstrating respect and minimizing risks of harm. A participant described cautioning his organization's headquarters team: "there's going to be a lot of collateral damage if this decision is taken too quickly, too autocratically." One participant described the importance of clarifying who should be responsible for the decision, who should be consulted during the process, who should be informed of the outcome, and to whom should decision-makers be held accountable. However, engaging stakeholders is often "easy to say, but far more difficult to achieve." The international humanitarian worker who made this assertion went on to describe the importance of consulting with local actors, and working toward a closure plan that is "negotiated" rather than imposed.

Several participants suggested that the decisionmaking process should, at minimum, include the opportunity for national staff to raise questions and concerns. This process should include consulting with "and informing the staff, the teams, so that they feel that their voice is heard" and they are "able to express their disappointment, their anger, their frustration ... and to ensure that those are communicated back up to headquarters or upstream." A national staff member reported not being included in a project closure decision, and that in such circumstances "you don't feel as part of the team per se." In contrast, a participant who closed a project as head of mission described a long period of discussion to which national and international staff all contributed, and that national staff "were part of the discussion from the start, which I think is important in a lot of situations." In retrospect, she felt that the national staff members were much more realistic about the situation than she and her international colleagues had been.

Several participants raised additional questions related to representation and decision-making. A national staff member who was a project coordinator in a post-conflict setting that had also experienced natural disasters explained that decisions were often taken at an international level and so did not sufficiently account for local or even national-level points of view. Describing the importance of identifying concerns at these levels, he reported that "sometimes those arguments don't even come up because there is lack of representation" from people working directly with the affected population. A participant with a human resources and finance background reported that people with these sets of expertise are rarely included in the operational decision-making around project closure. She believed that they should be included more given the important ramifications pertaining to human resources and finance when projects are closing.
Transparency is also needed within organizations, especially toward national staff. A participant described how there are usually rumors that circulate within the project team if there is a lack of clear communication, since "at the time that the decisions are being made of closing, everybody knows, and nobody knows officially." This situation "creates so many problems in any mission" and is a "really unstable situation for everybody." A former national staff member reported that while many international staff thought they were able to keep closure discussions a secret from national staff, this was rarely successful, and can further undermine trust.

\section{Implementing project closure: "show them that you care for what is going to happen next after you leave"}

Once the decision to close the project has been made, a particularly challenging phase begins. There may be additional opportunities to engage with local stakeholders in order to have "a better conversation with the country level emergency partners" explaining that "this is the amount of time we have and then give them options." The participant, a national staff member, suggested that engaging with local stakeholders would lead to a more robust partnership and greater likelihood of sustainable benefits once the project closes or transitions. In a similar vein, another participant expressed that humanitarian organization representatives need to sit down with the authorities and discuss how the final phases of the project should unfold: "not to say, ok, we're informing you of our decision, but it's really to [say] that they are invested, that they participate in the definition of this retreat."

If plans have been created and are well adapted to the situation, closing "shouldn't be haphazard. It should be a very structured approach." However, responsiveness to the ways that the situation has changed is needed. A participant ruefully noted that "there are ideals and then there is reality" and went on to explain that in closing projects, "realities are not linear. Not everything can be fitted into a logframe. Or these series of changes, if this happens and this happens, we will achieve that. I mean, life doesn't work like that." Another participant described how the project often evolves from its initial design due to changing needs of the affected populations, for institutional reasons or because of the funding that is available. He argued that understanding these elements and adjusting the approach to closure is necessary to "close down coherently and ethically."

Implementing an effective closure requires particular expertise, as well as a clear understanding of the overall arc of the project. Reflecting on her first experience closing a project which took place in a country that 
experienced a protracted armed conflict, a participant emphatically stated that it should not be an inexperienced head of mission who is responsible for the project closure. Some organizations identify experts in project closure to consult with those who are responsible for it in a particular project, though a participant also expressed concern that sometimes, "organizations ... hire someone just to do the dirty job" of project closure. Another participant expressed that humanitarian organizations should have the humility to recognize their own needs for capacity building in this area-and to improve organizational approaches to the closing out of projects.

Two participants who both had extensive experience in humanitarian work discussed how those closing a project-often not the same people who initiated it-needed to know details about how the project was opened and unfurled. Underscoring the importance of leaving an account, one describing it as "humanitarian malpractice" not to leave careful documentation of what was done, who was involved, and what was promised, as well as what was not done and why. This "map of the minefield" was crucial for working with local partners in carrying forward with a handover. The other participant suggested that it would be ideal if the people who opened the project returned for its closure, or were at least available to consult remotely with the team if they had questions about the design and early implementation phases. The importance of expertise and knowledge of how the project was opened were described in terms of avoiding or minimizing harms such as insecurity and managing reputational risks associated with poor project closure.

Beyond expertise and different forms of knowledge, financial and other material resources were also identified as crucial for closing well. Several participants reported that having dedicated funding for the transition phase would, as expressed by a national staff member, "really help to have a methodical approach, take more time, and have a sustainable program going into the future."

The potential for harms during the closing phase was underlined by a participant who expressed that, along with the opening of a project, closure is the most dangerous in terms of potential for violence and insecurity. A participant described a method that she used as head of mission to avoid such an outcome when multiple health clinics were to be closed. She described, "in a very context-specific type of way, to prepare a sort of plan about what was the worst-case scenario of announcing the closure. And then to somewhat back-engineer a lot of actions on actions, timing, planning etc., on how to prevent the worst-case scenario."

Another concern was about data protection during the closure phase. Participants described the need to carefully plan how confidential project data, such as health and financial records, will be managed leading up to the closure. Similarly, several participants described how any distribution of project assets, such as vehicles and computers, needed to be thought through very carefully. In some instances, competing claims on such assets led to disagreement and conflict between local actors, and strained relationships. These participants expressed that it was therefore necessary to have a robust and clearly articulated plan for managing the disbursement of any project assets. A final concern about material remnants from the project was the possibility of environmental harm. A national staff member from East Africa argued forcefully that humanitarian projects should consider their environmental impact post-closure, including how potentially dangerous health waste will be safely disposed.

Closely engaging with people who have accessed the project's services, as well as local partners and national staff, remains a key concern for the closure phase. Describing his work in transitioning humanitarian relief projects in refugee camps, a participant reported that when "closing things down... there's a bit of a negotiation process to listen to partners, listen to what people are saying in the camps. And to then feedback and try and put together a robust transition strategy that... is responsive to people at the grassroots level, clients, also at the sub-national level." A participant described how community advisory boards can be a useful mechanism for receiving feedback about project closure, and another participant expressed that it helped to identify one or several leaders amongst the national staff who could help to plan and communicate aspects of project closure.

Demonstrating compassion and care for local communities and national staff during the closure phase is needed. For one participant, a national staff member who had gone on to become an international humanitarian worker in several other countries, compassion was the primary issue for a successful closure process: the "ethical thing is to say that we care for everybody, for the drivers, for the sick, for the people in the town... So just show them that you care for what is going to happen next after you leave. There are infinite ways of doing that." She emphasized that humanitarian workers should seek to understand why people are anxious or angry, remembering that "we are all humans, and we are scared when there is a change." Therefore, part of demonstrating respect is maintaining open communication, "telling them how it's gonna be, keep a timeframe for them, and tell them that you care for them." Several participants also spoke about steps that humanitarian agencies can take to support national staff during the closure process, and described this as being part of the "duty of care" toward those who had worked with and for them. Specific examples included providing training that could help 
them secure other jobs, offering support for writing CVs and cover letters, and providing fair severance packages even where these are not required by law.

The success of project closure is directly related to whether and how services will continue to be available to the community. Participants expressed this as an ethical concern in relation to concepts of sustainability, continuity, or legacy of the project. A particularly challenging aspect of closure, however, is that when approaching a handover or transition to another organization or entity, humanitarians may need to accept a range of compromises. For example, the organization's clinical guidelines or standards of care may need to be altered to harmonize with those of the Ministry of Health, and humanitarian workers will need to accept a loss of control over project components that they had developed. In some instances, particularly during situations of armed conflicts, international NGOs have reservations about their handover partners but may have few other options. These realities can be distressing for some humanitarian workers as things "aren't always pretty" with a handover and humanitarians do not have control over what will unfold later on. For example, a participant explained that if a project was organized in a way that empowered women to play leading roles, this may be lost once a handover takes place. A participant noted that such challenges can be compounded due to the fact that the humanitarian organization's focus has likely shifted elsewhere, toward other projects or new initiatives and funding appeals, and there may be less attention given to support the project that is closing.

\section{Post-closure: "did it change something?"}

Participants consistently described a good closure as one that led to sustainability of services for the community through handover to local NGOs or governments, or transition to a development approach. A participant described this as the "bottom line" of closing well. Humanitarian organizations should work with their partners so that the conditions are in place for continuity of services after closure. A participant described how this goal required transfer of knowledge and skills, as well as resources, including leaving behind sufficient supplies such as medications. A national staff member linked this emphasis to the do-no-harm principle, expressing that "You know, you could start something and you could leave it in a state that could cause more harm in a particular community, because we haven't really looked at sustainability." A national staff member also noted that a poorly organized project closure might result in heightening tension and divisions within the local population.

In line with this emphasis on sustainability, several participants reframed metrics for success. One argued that humanitarian NGOs should gauge their success by whether their partnering organizations were, on balance, strengthened through the collaboration. Two participants suggested that a key indicator of success is whether one would be able to return and restart a project in the same locale later, and that the closure had not violated trust in a way that would make it difficult for another NGO to work in that community in the future.

A final ethical concern described by participants is the responsibility to learn from closure experiences and apply those lessons to future projects. Formal evaluations, however, are rarely done. A participant with extensive experience in humanitarian action felt that new models of participatory post-closure evaluation should be developed. Another participant expressed that "the ideal, ideal, ideal for me, would be after the closure of the project, to come back to see... did it change something? ... but we sadly don't have the money to do that, and the funders don't understand this, regardless of whether it's development or humanitarian." Another participant identified post-closure evaluation as being more frequently practiced in the development sector than the humanitarian sector. Practices of documentation and debriefing are also inconsistent, so opportunities for organizational learning are often missed. Several participants described an ethical obligation to apply lessons from challenging closure experiences during future projects.

\section{Discussion}

This study illuminates humanitarian workers' experiences of and perspectives on ethical concerns in planning and implementing closures, and illustrates at least some of the ethical complexities associated with ending, handing over, or transitioning a humanitarian project. It also points to opportunities to promote ethically sound project closures.

These findings contribute to a wider discussion on humanitarian project closure that has arisen over the past two decades (Lee and Özerdem 2015) and to explorations of ethical obligations in humanitarian action (Broussard et al. 2019; Slim 2015). Within the humanitarian sector, interest in project closure and "exit strategies" specifically has been spurred by a range of factors including increased understanding of harms associated with poorly planned and executed project closures (Maxwell 1999),protracted humanitarian crises and mass population displacements that make closure elusive, as well as an increasing conceptualization of humanitarian response and development approaches as interconnecting.

As the interviewees described their experiences across the stages of the project cycle, their observations contained recurrent ethical concerns, pointing to overlapping understandings of what it means to close a project 
well (see Fig. 1). These ethical concerns intersect broadly with those identified in a recent review of gray and academic literature on the ethics of closing humanitarian projects (Pal et al 2019), which found responsible planning, collaboration, adaptability, transparency, minimizing harms, sustainability, and fairness frequently cited as key ethical considerations.

One of the most poignant ethical concerns highlighted in our study (and notably not identified in the review by Pal et al, 2019) is the need to demonstrate care for local communities and staff. This was expressed by several participants in relation to feelings of compassion towards people most directly affected by a project closure. It was described both as an orientation to interpersonal interaction (e.g., attentive listening, expressing concern), as well as in terms of practical actions of assistance (e.g., support for local staff to seek new employment). These features point to the importance of articulating a relational ethics in humanitarian action and to ethical virtues that support caring engagement between humanitarian workers and the communities they serve (Hunt et al, 2014). These concerns are linked to the motivations of many humanitarian workers. Lisa Fuller, in her study of the ethics of opening and closing humanitarian projects, describes how a humanitarian worker '“... didn't feel that he had committed to a particular disease, or to a particular crisis, but rather, he said, 'I committed to helping people in this community"' (Fuller 2006 p. 63) and that this shaped his understanding of his obligations toward the people with whom he was working.

We observed that several of the participants who strongly expressed the importance of demonstrating care toward local communities and staff were themselves national staff members. It is possible that their inclusion in the study sample led to more attention to these elements, including practical ways that humanitarian organizations could demonstrate concern for local staff that would lose employment following the end of a project. It is of note that few gray or academic literature sources identified in the review by Pal et al (2019) included perspectives of national humanitarian workers.

In considering demonstrations of care and concern, it is critical to acknowledge that underlying many if not most relationships in humanitarian action are steep power differentials. Asymmetries of power exist, for example, between national and international staff (Redfield 2012), and influence their respective roles in decisionmaking and also how they will be affected by a project closure. They are also likely to influence perceptions of

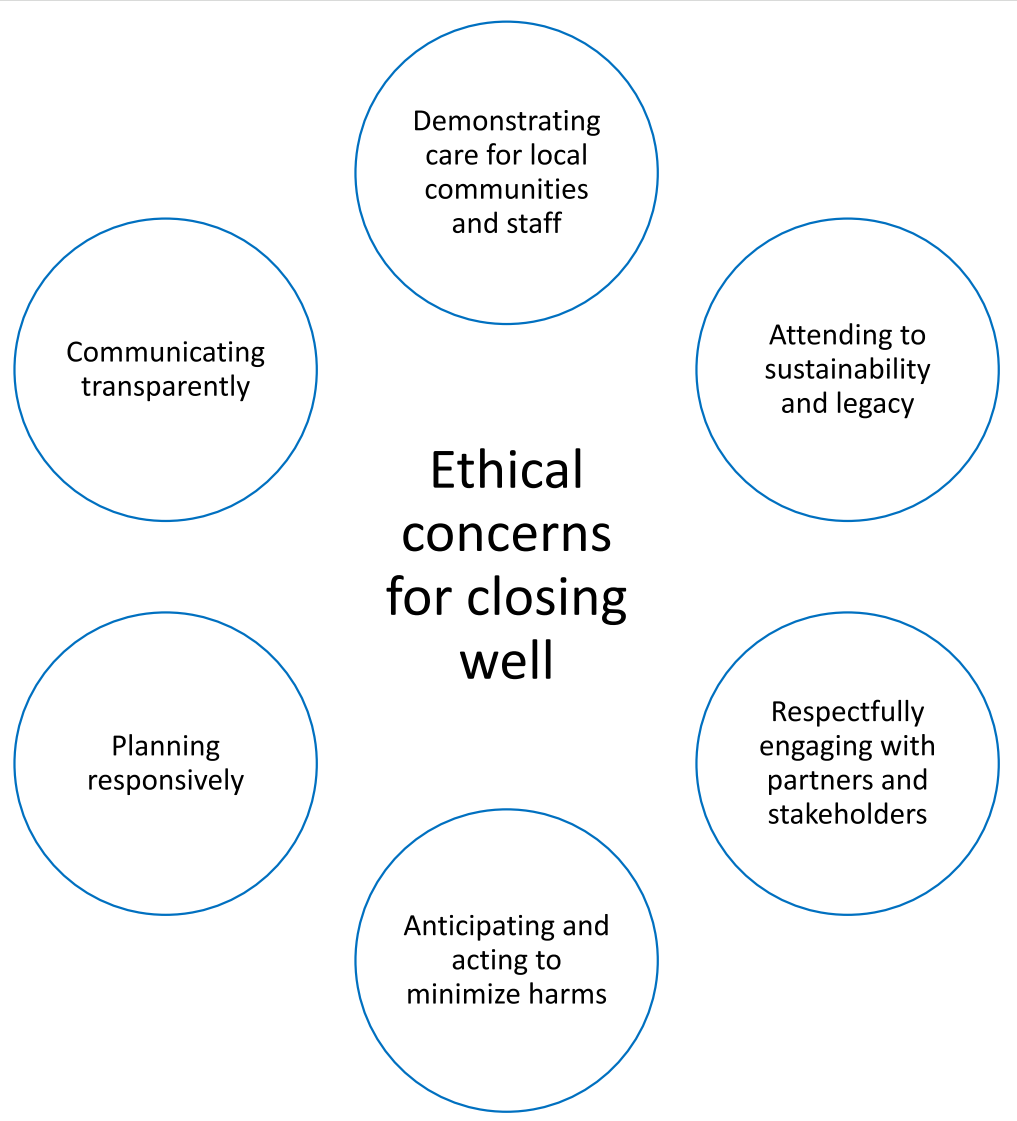

Fig. 1 Ethical concerns for closing well: perspectives of national and international humanitarian workers 
ethical project closure among members of local communities. The consequences of these differentials exist in many areas of humanitarian action (Jamar 2016; Roth 2012), but may be especially salient for project closure due to the impacts of such decisions. Addressing power differentials and promoting the agency of local communities and project staff are especially important when planning and implementing closure, and will impact the long-term effectiveness of the project and sustainability of activities.

A central emphasis across participants in the study was the importance of attending to sustainability of services and project legacy. Several participants identified this concern as being the most important aspect of an ethical project closure. There is an inherent tension, however, that exists given the temporary nature of humanitarian relief efforts (Ford et al. 2010). These initiatives are primarily intended to be short-term responses to situations of acute need. Yet, emphasizing the legacy of a humanitarian project is consistent with the do-noharm principle and with early recovery efforts, and has been described as a measure of project success (British Red Cross n.d.; McGoldrick 2011). In particular, handover and transition scenarios present important opportunities to increase the likelihood that quality services will be accessible after the project ends (Gerstenhaber 2014). Concern for sustainability can be addressed from the earliest stages of a project, including design and funding considerations, and continue throughout the process (Pal et al 2019). This vision is consistent with the Sphere Handbook's Minimum Standards for $\mathrm{Hu}-$ manitarian Response which guides humanitarian organizations to "plan a transition or exit strategy in the early stages of the humanitarian programme that ensures longer-term positive effects and reduces the risk of dependency" (Sphere Association 2018).

Several authors writing about ethical project closure have described special obligations arising in situations of project closure (Fuller 2006; Rubenstein 2015), and how the nature of a humanitarian project creates particular duties on the part of humanitarian organizations towards populations with whom they have been working, and varied local stakeholders. Hunt and Miao (2018) draw on Richardson's conceptualisation of moral entanglements (Richardson 2012) to develop an account of how these obligations are increased as projects are longer in duration, the services provided are more comprehensive, and local communities are more reliant on the assistance that is provided. A key feature of these obligations relates to respectfully engaging with people who will be affected by the closure throughout its planning and implementation. For study participants, this included respectfully engaging with partners and other stakeholders, including local governments and civil society organizations, as well as other humanitarian organizations. Several participants referred to processes of negotiation with local actors and were concerned about plans and decisions being imposed on communities or partner organizations, especially where engagement was lacking. As well as a means of demonstrating respect and contributing to accountability (IFRC 2016), engagement with local actors promotes more realistic planning, capacity building, and sustainability of project activities after closure (Lee and Özerdem 2015; British Red Cross n.d.). Yet approaches that involve engagement and negotiation may be perceived as particularly challenging to achieve in an acute humanitarian response, where there is pressure to make decisions quickly and act decisively (Sphere Association 2018). It is of note that even in such contexts of perceived acuity and urgency, our study participants advocated for more engagement with stakeholders and asserted that this was important and feasible.

A key obligation described by all participants is to plan and implement project closure in ways that avoid or minimize harms for individuals and groups who have been receiving assistance, and to be proactive in anticipating and addressing sources of potential harm. This concern reflects the broad emphasis in humanitarian ethics focusing attention to the ways that humanitarian activities can lead to unintended harms for communities affected by crises, and the responsibility to take steps to avoid, minimize or mitigate such harms where possible (Anderson 1999).This approach was also linked to responsiveness in planning, requiring keen sensitivity to local contextual factors and adaptability in the face of shifting circumstances. Risks of harm are diverse, and include loss of services, feelings of abandonment, heightening of community tensions or misuse of project data, as well as risks for wider communities due to economic disruption or insecurity during and after closure, for project staff due to loss of employment or feelings of distress, or for the organization if there is reputational harm (Lee and Özerdem 2015; Anderson et al. 2012; Abu-Sada and Mambetova 2012; Gerstenhaber 2014; Solidarités International 2016). A concern to minimize risk is reflected by the Core Humanitarian Standard's goal that "Communities and people affected by crises are not negatively affected and are more prepared, resilient and less at-risk as a result of humanitarian action." (Alliance $\mathrm{CH} 2014$ p. 9). Responsive planning and ongoing risk analysis are needed so that potential harms are identified and avoided, or minimized and mitigated (Maxwell 1999). A tangible means of mitigating potential harms is for organizations and teams to apply what has been learned in previous closures and to maintain an institutional memory of closure experiences (Hunt and Miao, 2018). Study participants also described strategies they used to carefully consider potential harms and then 
work backwards to identify opportunities to head off these risks, a process linked to the ethical capacity of foresighting (Kurasawa, 2007).

In contrast to the review by Pal et al (2019), in our analysis of the interviews we did not identify fairness or justice as a separate element. Instead, justice can be seen as a consideration that is entangled with multiple ethical concerns and which arises over the stages of a humanitarian project. For example, minimizing harms included concern for the consequences of how project assets are distributed after closure and whether it will be perceived as fair, or coopted to the advantage of certain groups. Likewise, questions of equity are highly relevant in how local staff who will lose employment after project closure are treated (which also links to demonstrating care for local communities and staff). The participants' narratives also included a range of considerations of justice and accountability in the process of making and enacting a decision to close which are linked to the concept of procedural fairness.

Procedural fairness focuses attention on how a decision is made and how it is implemented, rather than examining the ethical justification of a decision whether to close a project. In this sense, procedural fairness may be upheld even when people disagree about the outcome of a decision. It is especially important because resource allocation decisions in humanitarian action are often contentious (Hurst et al. 2009). It is related to concerns of respect, participation and justice. For example, participants in our study described the importance of communicating transparently about the reasons why a project was being closed and the steps that would be taken from the outset. They reported moral distress when they were prevented from providing such information to communities with whom they worked, reflecting a broader concern in humanitarian ethics for transparent communication and accountability (Broussard et al. 2019) (we note that there may be reasons for delaying communication of information related to project closure in some particular circumstances, such as minimizing harms if there were credible concerns for security). Likewise, participants identified concerns about inclusion and participation in decision-making process. These issues might be understood through the lens of epistemic justice, which relates to the link between power and knowledge, including issues of how credibility and authority are assigned to different actors and to different types and sources of knowledge (Fricker 2007). Procedural fairness is related to who is offered the opportunity to join in a deliberative process, and how information is communicated and to whom; where transparency and participation are lacking or inconsistent, fairness may be undermined, and harms may result.

There are, finally, ethical considerations that pertain specifically to the experience of humanitarian actors. As noted above, humanitarians may experience moral distress when they are unable to act in ways that are consistent with their values (Gustavsson et al. 2020), such as when they feel committed to continue helping a community whose needs are significant and ongoing, yet being unable to do so due to a lack of funding. They may also feel ethical tension of being pulled in two directions: a sense of obligation to continue helping communities with whom they have been working, yet committed to provide assistance to helping those communities where needs are greatest (Fuller 2006). Closure may thus lead to dissonance for humanitarian workers if the closure of a project that has been helping a community with important ongoing needs feels at odds with their very motivations for becoming a humanitarian worker in the first place: to be able to help people in need (De Waal 2010).

This exploratory study has enabled us to clarify aspects of what is ethically at stake in project closure from the perspectives of a diverse group of national and international humanitarian workers. In interviewing humanitarian workers, it is unsurprising that we heard mostly about the responsibilities of humanitarian organizations and their staff. In future research on this topic it would be highly valuable to engage further with the perspectives of local communities affected by project closures, as well as local organizations and government agencies, to better understand the ethics of project closure from their perspectives. Such an inquiry could shed light on how ethical responsibilities and agency (their own and those held by others) are understood by these stakeholders. The study sample for the current inquiry included individuals who had participated in humanitarian responses in diverse locations and who were affiliated with many different humanitarian organizations. This diversity fits well with the exploratory nature of the study aiming for a broader view across the humanitarian sector, but also reflects one of its key limitations due to the wide scope.

\section{Conclusion}

This study draws attention to the ways that national and international humanitarian workers experience ethical commitments and values in the process of project closure, and their perspectives on opportunities to promote better alignment between values and actions, and on overcoming challenges for doing so in these situations. It is clear that project closure can be a particularly difficult aspect of humanitarian action and a challenging experience for both national and international staff. Closing projects involves making multiple complex decisions with imperfect information. This situation may be compounded by features including stress, inter-personal conflict, resource limitations, insecurity, competing interests, and urgent needs elsewhere. It inevitably involves 
ethical trade-offs and tragic choices where something of ethical significance must be given up (Hunt et al 2013). In this way, closure may leave humanitarian workers with a lingering sense of ethical strain, or moral residue, especially when communities with elevated needs will have diminished access to quality care as a result of decisions made (Gustavsson et al. 2020).

As illustrated by the narratives of the participants in this study, there are a range of ethical considerations that can serve as useful resources to promote closing well, at least as well as possible in often highly constrained situations. While sustainability of access to services was identified by our participants as a central feature of an ethical project closure, the findings shed light on a range of other aspects that are constitutive of closing well and that also warrant careful attention. It is important to acknowledge that opening a life-saving project can still be ethically justified, even in circumstances where it is difficult to imagine, at the outset of the project, what a successful closure might look like. Careful attention to closure across the lifecycle of the project is needed to minimize potential harms for affected populations.

The analysis presented in this article was one source of inspiration for developing an ethics guidance note for people involved in the closure of a humanitarian project in which we identify ethical capacities, ethical principles, and ethical processes to orient project closure (see https://humanitarianhealthethics.net/ethics-and-the-closure-of-humanitarian-healthcare-projects/). We welcome further investigation and discussion of ways to improve support for humanitarians and communities receiving assistance as they anticipate, carry out, and are impacted by project closure.

\section{Abbreviation}

NGO: Non-governmental organization

\section{Acknowledgements}

We are grateful to the interview participants and to Monika Noble for her work as a research assistant. We thank our project partner, Médecins du Monde/Doctors of the World-Canada for their support of this project, and all those who attended our project feedback meeting on 24 May 2019, in Montreal, Canada.

\section{Authors' contributions}

All authors contributed to developing the initial idea for this manuscript. $\mathrm{MH}$ wrote the first draft, and all authors made substantial contributions as the paper was revised. MH conducted interviews with participants, wrote interview synopses and coded all transcripts. LE independently coded two transcripts. The authors participated in the data analysis process and approved the final version of the manuscript.

\section{Funding}

This research was supported by a grant from the Québec Population Health Research Network (QPHRN). Matthew Hunt is supported by a Research Scholar Award from the Fonds de Recherche du Québec-Santé.

\section{Availability of data and materials}

The data analyzed during the current study are not publicly available due to confidentiality considerations. Additional illustrative quotations (excerpts) from the transcripts may be requested from the corresponding author.

\section{Competing interests}

The authors declare that they have no competing interests.

\section{Author details}

${ }^{1}$ School of Physical and Occupational Therapy, McGill University, and Centre for Interdisciplinary Research in Rehabilitation, 3654 Promenade Sir William Osler, Montréal, QC H3G 1Y5, Canada. ²Department of Philosophy,

Department of Health Administration and Policy, George Mason University, 4400 University Avenue, Fairfax, VA 22030, USA. ${ }^{3}$ Public Health Office of the CIUSSS de la Capitale-Nationale, and Department of Preventive and Social Medicine, Université Laval, 2400 Avenue D'Estimauville, Ville de Québec G1E 6W2, Canada. Ingram School of Nursing, McGill University, 680 Rue Sherbrooke Ouest, Montréal, QC H3A 2M7, Canada. ${ }^{5}$ School of Physical and Occupational Therapy, McGill University, 3654 Promenade Sir William Osler, Montréal, QC H3G 1Y5, Canada. ${ }^{6}$ Department of Philosophy, Université de Montréal, 2910 Boulevard Édouard-Montpetit, Montréal, QC H3T 1J7, Canada.

Received: 23 April 2020 Accepted: 25 October 2020

Published online: 24 November 2020

\section{References}

Abu-Sada C, Mambetova K (2012) Dilemmas, challenges, and ethics of humanitarian action: reflections on Médecins Sans Frontières' Perception Project. McGill-Queen's University Press, Montreal

Alliance CH (2014) Core humanitarian standard on quality and accountability. CHS Alliance, Groupe URD and the Sphere Project. Available from: https:// corehumanitarianstandard.org/files/files/Core\%20Humanitarian\%2 OStandard\%20-\%20English.pdf

Anderson MB (1999) Do no harm: how aid can support peace--or war. Lynne Rienner Publishers, London

Anderson MB, Brown D, Jean I (2012) Time to listen: hearing people on the receiving end of international aid. CDA Collaborative Learning Projects, Cambridge

British Red Cross (n.d.) Exit strategy guidance. Available from: http://www. livelihoodscentre.org/documents/20720/25507/EN_Exit_strategy.docx

Broussard G, Rubenstein LS, Robinson C, Maziak W, Gilbert SZ, DeCamp M (2019) Challenges to ethical obligations and humanitarian principles in conflict settings: a systematic review. J Int Humanit Action. 4(1):15

De Waal A (2010) The humanitarians' tragedy: escapable and inescapable cruelties. Disasters. 34:S130-S137

Ford N, Bedell R (2001) Justice and MSF operational choices. Médecins sans Frontières-Holland, Amsterdam

Ford N, Zachariah R, Mills E, Upshur R (2010) Defining the limits of emergency humanitarian action: where, and how, to draw the line? Public Health Ethics. 3(1):68-71

Fricker M (2007) Epistemic injustice. Power \& the ethics of knowing. Oxford University Press, Oxford

Fuller L (2006) Justified commitments? Considering resource allocation and fairness in Medécins Sans Frontières-Holland. Dev World Bioeth 6(2):59-70

Gerstenhaber R (2014) Handover Toolkit 2.0 "Success is also measured by what you leave behind". Médecins Sans Frontières, Geneva Available from: https:// evaluation.msf.org/sites/evaluation/files/handover_toolkit.pdf

Global CCCM Cluster. Camp closure guidelines. 2014. Available from: http://www. globalcccmcluster.org/system/files/publications/Camp_Closure_Guidelines. pdf

Gustavsson ME, Arnberg FK, Juth N, von Schreeb J (2020) Moral distress among disaster responders: what is it? Prehosp Disaster Med:1-8

Hunt M, Miao J (2018) Moral entanglements and the closing of humanitarian projects. In: Ahmad A, Smith J (eds) Humanitarian action ethics. Zed Books, London, pp 22-29

Hunt M, Schwartz L, Sinding C, Elit L (2014) The ethics of engaged presence: a framework for health professionals in humanitarian assistance and development work. Dev World Bioeth. 14(1):47-55

Hunt M, Sinding C, Schwartz L (2013) Tragic choices in humanitarian healthcare practice. J Clin Ethics. 23(4):338-344 
Hurst SA, Mezger N, Mauron A (2009) Allocating resources in humanitarian medicine. Public Health Ethics. 2(1):88-89

IFRC. Exit strategy guidance. 2016. Available from: https://media.ifrc.org/ifrc/wpcontent/uploads/sites/5/2017/01/TOOL-16-Exit-strategy-guidance.docx

Jamar A (2016) Breakfast in Aidland: quotidian relations and structural contradictions. Allegra Lab

Kurasawa F (2007) The work of global justice: human rights as practices. Cambridge University Press, United States of America

Lee SY, Özerdem A (2015) Exit strategies. In: Ginty RM, Peterson JH (eds) The Routledge companion to humanitarian action. Routledge, New York, pp 372 384

Lincoln YS, Lynham SA, Guba EG (2011) Paradigmatic controversies, contradictions, and emerging confluences, revisited. Sage Handb Qual Res 4: 97-128

Maxwell D (1999) Programmes in chronically vulnerable areas: challenges and lessons learned. Disasters. 23(4):373-384

McGoldrick C (2011) The future of humanitarian action: an ICRC perspective. Int Rev Red Cross. 93(884):965-991

Orach CG, De Brouwere V (2005) Integrating refugee and host health services in West Nile districts, Uganda. Health Policy Plan. 21(1):53-64

Pal N, Eckenwiler L, Hyppolite S-R, Pringle J, Chung R, Hunt M (2019) Ethical considerations for closing humanitarian projects: A scoping review. J Int Humanit Action. 4:17

Redfield P (2012) The unbearable lightness of ex-pats: double binds of humanitarian mobility. Cult Anthropol. 27(2):358-382

Richardson HS (2012) Moral entanglements: the ancillary-care obligations of medical researchers. Oxford University Press, Oxford

Roth S (2012) Professionalisation trends and inequality: experiences and practices in aid relationships. Third World Q. 33(8):1459-1474

Rubenstein J (2015) Between Samaritans and States: the political ethics of humanitarian INGOs. OUP, Oxford

Slim H (2015) Humanitarian ethics: a guide to the morality of aid in war and disaster. Oxford University Press, Oxford

Solidarités International. Solidarités international operational framework. 2016. Available from: https://www.solidarites.org/wp-content/uploads/2017/05/ Solidarités-International-operational-framework.pdf

Sphere Association (2018) Sphere handbook: Humanitarian charter and minimum standards in humanitarian response. Practical Action. Available from: https:// spherestandards.org/wp-content/uploads/Sphere-Handbook-2018-EN.pdf

Thorne S (2000) Data analysis in qualitative research. Evid Based Nurs 3(3):68-70

Thorne S (2016) Interpretive description: qualitative research for applied practice. Routledge, New York

World Health Organization (n.d.) Chapter 11 phasing out. In: Managing WHO humanitarian response in the field Available from: https://www.who.int/hac/ techguidance/tools/manuals/who_field_handbook/11/en/

\section{Publisher's Note}

Springer Nature remains neutral with regard to jurisdictional claims in published maps and institutional affiliations.

\section{Submit your manuscript to a SpringerOpen ${ }^{\circ}$ journal and benefit from:}

- Convenient online submission

- Rigorous peer review

- Open access: articles freely available online

- High visibility within the field

- Retaining the copyright to your article

Submit your next manuscript at $\boldsymbol{\nabla}$ springeropen.com 